\title{
LIMITES DA TOLERÂNCIA E LIBERDADE DE EXPRESSÃO: CONSIDERAÇÕES À LUZ DO PENSAMENTO DE JOHN RAWLS EM UMA TEORIA DA JUSTIÇA
}

\author{
LIMITES DE TOLÉRANCE ET DE LIBERTÉ D'EXPRESSION: CONSIDÉRATIONS À LA LUMIÈRE DE \\ LA PENSÉE DE JOHN RAWLS DANS UNE THÉORIE DE LA JUSTICE
}

Wanderley Martins Cunha*

\section{RESUMO}

Partindo das análises apresentadas no Foro Internacional sobre Intolerância realizado pela UNESCO em 1997 e também da constatação de que há uma espécie de intolerância difusa que contém, em estado latente, os racismos, fundamentalismos, integralismos, fascismos que ainda nos assombram, o presente texto assume a perspectiva teórica segundo a qual a necessária promoção da tolerância, virtude particularmente importante para as democracias liberais constitucionais, exige em contrapartida a clareza quanto àquilo que constitui o intolerável, exigência que nos coloca perante o difícil problema dos limites da tolerância. Assim sendo, o escopo principal deste texto - tendo como pressuposto a necessidade de assinalar as margens para além das quais a tolerância torna-se indiferença, passividade ou cumplicidade com o intolerável, conforme assinala Paul Ricoeur - é abordar, à luz da teoria da justiça como equidade de John Rawls, a problemática dos limites da tolerância e sua incidência no âmbito da liberdade de expressão, considerada como uma das liberdades básicas fundamentais numa sociedade democrática.

PALAVRAS-CHAVE: John Rawls. Intolerância. Justiça. Tolerância. Liberdade de expressão.

\section{RÉSUMÉ}

D'après l'analyse présentée au Forum International sur l'intolérance organisé par l'UNESCO en 1997 et aussi du fait qu'il y a une sorte d'intolérance diffuse qui a, dans un état latent, le racisme, l'intégrisme, le fondamentalisme, le fascisme qui nous hantent encore, ce texte prend le point de vue théorique selon lequel la nécessaire promotion de la tolérance, vertu particulièrement importante pour les démocraties libérales constitutionnelles, d'autre part exige de la clarté sur ce qui constitue l'intolérable et cette exigeance nous met face au problème difficile des limites de tolérance. Par conséquent, l'objectif principal de ce texte en prenant comme présupposition la nécessité de marquer les marges au-delà desquelles la tolérance devient indifférence, passivité ou complicité avec l'intolérable, comme le souligne Paul Ricoeur - est de résoudre, à la lumière de la théorie de la justice l'équité preconisée John Rawls, le problème des limites de tolérance et de son impact sur la liberté d'expression, considérée comme l'une des libertés fondamentales dans une société démocratique.

MOTS-CLÉS: John Rawls. Intolérance. Justice. Tolérance. Liberté d'expression.

\section{INTRODUÇÃO}

Virtude considerada particularmente importante nas sociedades liberais, a tolerância, de acordo com Paul Ricoeur (2000, p. 21), é a confirmação do fato maior predominante nas

\footnotetext{
* Doutor em filosofia pela PUC-SP e Mestre em filosofia social e política pela UFMG. Professor de filosofia da PUC Minas. E-mail: wmcunha@ig.com.br.
} 
democracias liberais constitucionais: o "fato do pluralismo", isto é, a existência de uma pluralidade de crenças e convicções heterogêneas e incompatíveis. Considerando que, por um lado - no plano institucional — a prática da tolerância liga-se à ideia de abstenção; e, por outro lado - no plano individual — ela está articulada à ideia de admissão, pode-se dizer, numa rápida caracterização, que "a tolerância consiste na abstenção de intervenção na ação e na opinião do próximo, mesmo que se tenha poder de fazê-lo e mesmo que se desaprove ou não se aprecie a ação ou opinião em questão" (MENDUS, 2013, p. 1030), admitindo-se portanto no outro uma maneira diferente de pensar e agir. Nesse sentido, a prática da tolerância deve alicerçar-se na aceitação daquilo que Montaigne (1972, p. 372) afirmou de forma lapidar: "Cada homem traz em si a forma completa da condição humana". Ou seja, a tolerância implica dar ao outro o mesmo estatuto concedido a nós mesmos; implica, em suma, aceitar e respeitar que na sua singularidade o outro é tão humano quanto nós.

Contudo, a partir das análises apresentadas no Foro Internacional sobre a Intolerância realizado pela UNESCO em 1997, e levando-se em conta também o que se observa no cenário sócio-político atual, uma constatação deve ser feita: existe uma intolerância residual que ameaça a ainda frágil prática da tolerância, duramente conquistada ao longo dos últimos séculos. Ou seja, há uma espécie de intolerância difusa que contém, em estado latente, os racismos, fundamentalismos, integralismos, fascismos que tantas sombras projetam sobre a nossa a humanidade. Infelizmente facilmente se constata que um verdadeiro mecanismo de intolerância - que "consiste na convicção de que os outros não pensam, não sentem, não reagem como nós (qualquer que seja esse "nós"), que nos consideramos a essência da humanidade e da civilização" (HÉRITIER, 2000, p. 24) — ainda está fortemente arraigado na conduta de várias pessoas e grupos. Percebe-se então, de acordo com as várias análises efetuadas no debate organizado pela UNESCO em 1997, que o núcleo que contém em embrião as várias manifestações de intolerância articula-se em torno da "demonização da diferença", levada ao paroxismo na eliminação do outro. Perante tal quadro, emerge como um imperativo cada vez mais atual a urgência de se enfrentar esse ódio e aversão ao dessemelhante.

No contexto sócio-histórico que caracteriza as primeiras décadas do século XXI, a promoção da tolerância, necessária para se combater a crescente onda de intolerância, requer, entretanto, conforme nos lembra Paul Ricoeur (1991), a clareza quanto àquilo que constitui o intolerável, quanto àquilo que não pode ser tolerado em hipótese alguma. Ou seja, repudiando-se a defesa do absurdo ligado à idéia de uma tolerância ilimitada, é preciso 
Artigo: Limites da tolerância e liberdade de expressão: considerações à luz do pensamento de John Rawls em Uma teoria da justiça

assinalar as margens para além das quais a tolerância torna-se indiferença, passividade ou cumplicidade com o intolerável. Ao se introduzir a discussão acerca do intolerável, coloca-se então de forma premente e, pode-se dizer, até dramática, a questão acerca dos limites da tolerância e/ou da justificativa para a intolerância.

Se concordarmos, por exemplo, que é intolerável a utilização dos meios de comunicação para expor ideias racistas, xenófobas, sexistas etc., verifica-se que quando isso acontece emergem invariavelmente discussões ligadas à "ética das mídias" e aos limites da própria liberdade de imprensa. Considerando a liberdade de imprensa como vetor de uma liberdade mais fundamental para o ser humano que é a liberdade de expressão, constata-se, como pano de fundo dessas discussões, a existência de um nível de questionamento mais complexo que pode ser ilustrado com as seguintes interrogações: Em que medida a veiculação midiática da intolerância pode justificar uma limitação da liberdade de expressão? Se a liberdade de expressão puder ser limitada, qual o critério? Este tipo de problemática conforme Canto-Sperber assinalou em sua conferência intitulada "Tolerância, neutralidade e pluralismo na tradição liberal" proferida no foro acima citado -, incide vigorosamente nas perspectivas defendidas pela tradição liberal. De acordo com a proposta dessa tradição, a liberdade de pensar sem restrição, de dizer o que se pensa, de ir aonde se deseja, de se associar como e com quem quiser deve ser honrada ou realizada de maneira máxima no seio de uma sociedade. Reconhecendo um valor intrínseco em não interferir nas ações e nas opiniões alheias, e preconizando que o Estado deve se abster de se pronunciar sobre o que ele pode tolerar, a liberdade de opinião e a tolerância constituem elementos de grande importância nas sociedades marcadas pelo ideário liberal. Assim sendo, a partir de premissas liberais, como pensar, por exemplo, as questões anteriormente elencadas referentes aos limites da tolerância e da liberdade de expressão?

No presente texto, considerando a teoria liberal de justiça elaborada por John Rawls, uma referência obrigatória no campo da filosofia política contemporânea, procuraremos verificar em que medida a questão dos limites da tolerância e sua incidência no âmbito da liberdade de expressão pode ser abordada à luz da teoria da justiça como equidade. Para tanto, nos limites de uma exploração propedêutica da obra Uma teoria da justiça, faz-se necessário, como ponto de partida da reflexão aqui proposta, apresentarmos uma visão geral da Teoria da justiça como equidade. 


\section{TEORIA DA JUSTIÇA COMO EQUIDADE: VISÃO GERAL}

No capítulo introdutório de Uma teoria da justiça, John Rawls apresenta algumas das principais ideias da teoria da justiça que pretende desenvolver. Começa descrevendo o papel da justiça na sociedade, apresentando-a como a virtude primeira das instituições sociais, de tal forma que ela não pode ser objeto de qualquer compromisso. Para averiguar a veracidade do que foi dito, deve-se "elaborar uma teoria da justiça à luz da qual estas afirmações possam ser interpretadas e avaliadas" (RAWLS, 1997, p. 4). Considerando que uma sociedade é simultaneamente marcada por conflito e identidade de interesses, é preciso que haja princípios que, por um lado, permitam a opção dentre as várias formas de ordenação social que determinam uma justa divisão das vantagens e, por outro lado, validem um acordo sobre as partes distributivas adequadas. Os princípios que cumprem essa tarefa são os da justiça social. São eles que "fornecem um modo de atribuir direitos e deveres nas instituições básicas da sociedade e definem a distribuição apropriada dos benefícios e encargos da cooperação social" (RAWLS, 1997, p. 5). No entanto, os próprios princípios que visam definir o que é justo ou injusto numa sociedade são objetos de disputas. Apesar disso, Rawls (1997, p. 6) distinguindo entre "conceito de justiça" e as várias concepções de justiça — admite que se pode concordar com uma descrição de instituição justa, quando nela "não se fazem distinções arbitrárias entre as pessoas na atribuição de direitos e deveres básicos e quando as regras determinam um equilíbrio adequado entre reivindicações concorrentes das vantagens da vida social". Em seguida, após uma reflexão sobre o objeto primeiro da justiça, isto é, sobre "a forma pela qual as instituições sociais mais importantes distribuem os direitos e deveres fundamentais e determinam a divisão dos benefícios de cooperação em sociedade" (p. 7), Rawls assevera que na estrutura básica de qualquer sociedade, devido ao fato de elas favorecerem certas posições iniciais relativamente a outras, há desigualdades profundas que não podem ser justificadas pela invocação das noções de mérito ou valor. Por isso, "deve-se, então, considerar que uma concepção da justiça social fornece primeiramente um padrão pelo qual se deve avaliar aspectos distributivos da estrutura básica da sociedade" (p. 10). Para o filósofo, os princípios de justiça constituem apenas a parte mais importante de uma concepção de justiça, que por sua vez está ligada a um ideal de sociedade, isto é, a uma determinada "visão do modo como os objetivos e propósitos da cooperação social devem ser entendidos". Feitas essas considerações, John Rawls, na terceira seção do primeiro capítulo, expõe a ideia central de justiça como equidade. Ele introduz a questão dizendo que sua concepção de justiça 
Artigo: Limites da tolerância e liberdade de expressão: considerações à luz do pensamento de John Rawls em Uma teoria da justiça

generaliza e eleva a um nível superior a tradicional teoria do contrato social, na medida em que sua ideia condutora é aquela que assinala que os princípios da justiça aplicáveis à estrutura básica formam o objeto de um acordo original, ou seja, "aqueles que se comprometem na cooperação social escolhem juntos, numa ação conjunta (ato comum), os princípios que devem atribuir direitos e deveres básicos e determinar a divisão de benefícios sociais" (RAWLS, 1997, p. 11-12). Essa posição original ${ }^{1}$ equitativa, a partir da qual se elaboram os princípios da justiça, corresponde ao estado natural no contratualismo e, enquanto tal, deve ser vista como uma situação hipotética, cuja característica principal é o fato de os participantes do acordo original, encobertos por um véu de ignorância ${ }^{2}$, escolherem princípios da justiça resultantes de uma negociação eqüitativa, isto é, resultantes de um acordo estabelecido numa situação original de igualdade.

Para Rawls, no âmbito da concepção de justiça como equidade, uma das tarefas principais é a determinação de quais princípios da justiça são efetivamente escolhidos na posição original. Ele argumenta que tal escolha deve ser guiada pelo seguinte critério intuitivo: "pelo fato de o bem-estar de todos depender de um sistema de cooperação sem o qual ninguém pode ter uma vida satisfatória, a divisão de vantagens deveria acontecer de modo a suscitar a cooperação voluntária de todos os participantes, incluindo-se os menos bem situados" (RAWLS, 1997, p. 16). Assim sendo, sem pretender ser convincente para todos, no capítulo II - seção 11, Rawls apresenta, ainda de modo provisório, os dois princípios da justiça que seriam escolhidos na posição original de equidade:

\footnotetext{
${ }^{1}$ No $\S 4$ do capítulo I, Rawls sustenta que a posição original (PO) constitui o status quo inicial adequado que garante que os acordos nele alcançados são equitativos, donde decorre a concepção de "justiça como equidade". O conceito de posição original relaciona-se com a situação de escolha inicial filosoficamente preferível para os objetivos de uma teoria da justiça como equidade. "A ideia aqui é tornar nítidas para nós mesmos as restrições que parece razoável impor a argumentos que defendem princípios de justiça e, portanto, aos próprios princípios" (1997, p. 20). Desse modo, é razoável supor que as partes na PO são iguais, isto é, não há favorecimento de espécie alguma; também é razoável supor que os princípios que serão escolhidos são adequados às nossas ponderações sobre a justiça ou as alargam de forma aceitável (1997, p.22), isso pode exigir um processo de ajustamento mútuo de princípios e decisões (equilíbrio reflexivo).

${ }^{2}$ No $\S 24$, Rawls apresenta uma reflexão mais pormenorizada acerca deste dispositivo por ele criado para caracterizar melhor a simulação heurística de um estado primitivo no qual uma falta de informação sobre o estatuto e as condições reais de cada um possibilita a opção pelos princípios da equidade. Partindo da concepção de que - com base na ideia de Justiça procedimental pura - devem-se anular os efeitos das contingências específicas que induzem os homens a tentarem se beneficiar das circunstâncias naturais e sociais favoráveis, Rawls assinala que na posição original as partes estão situadas atrás de um véu de ignorância. Isto é, supõe-se que não se conhecem certos tipos de fatos particulares (status social, dotes naturais e habilidades de que se é portador etc.), não se tem conhecimento das circunstâncias particulares da própria sociedade em que a parte se insere e nem informações sobre a qual geração pertence. Além disso, todos desconhecem a própria concepção de bem, os traços característicos de sua psicologia etc. (1997, p. 147). O véu de ignorância, assegurando "não apenas que a informação disponível é relevante, mas também que é a mesma em todas as épocas" (1997, p. 149), é a condição essencial para que a perspectiva da posição original, indiferentemente da ocasião ou de quem a adota, possibilite a escolha sempre dos mesmos princípios.
} 
Primeiro: cada pessoa deve ter um direito igual ao mais abrangente sistema de liberdades básicas iguais que seja compatível com um sistema semelhante de liberdades para as outras.

Segundo: as desigualdades sociais e econômicas devem ser ordenadas de tal modo que sejam ao mesmo tempo (a) consideradas como vantajosas para todos dentro dos limites do razoável, e (b) vinculadas a posições e cargos acessíveis a todos. (RAWLS, 1997, p. 66).

Comentando essa primeira versão dos princípios de justiça, Rawls (1997, p. 65) salienta que deve haver, por um lado, uma distinção dos aspectos do sistema social que definem e garantem iguais liberdades básicas ${ }^{3}$ para todos e, por outro, os que especificam e estabelecem as desigualdades econômicas e sociais. Além disso, os dois princípios devem ser dispostos numa ordenação serial, tendo o primeiro princípio prioridade sobre o segundo. Isso implica que as liberdades básicas iguais defendidas no primeiro princípio só podem ser limitadas ou comprometidas quando entram em conflito umas com as outras, não podendo ser barganhadas em vista de maiores vantagens econômicas e sociais.

De acordo com o filósofo, o segundo princípio que versa sobre as parcelas distributivas contém duas expressões ambíguas: (a) "vantajosas para todos" e (b) "igualmente abertos a todos". Assim sendo, no $\S 12$ ele propõe um exame dele a partir de um duplo significado imediato de cada uma dessas expressões, gerando assim quatro possíveis interpretações desse princípio.

O primeiro significado de "vantajosas para todos" (chamemos de a1) liga-se ao princípio da eficiência $^{4}$ e o segundo (chamemos de a2) está ligado ao princípio da diferença ${ }^{5}$. Já a expressão "igualmente aberta a todos" pode significar: igualdade como carreiras abertas a talentos (chamemos de b1) ou igualdade como igualdade de oportunidades equitativas (chamemos de b2). Supondo que o princípio da liberdade igual para todos é satisfeito e que a economia é um sistema de mercado livre, o entrecruzamento das significações acima apresentadas gera quatro possíveis interpretações do segundo princípio da justiça como equidade:

\footnotetext{
${ }^{3}$ Elenco das liberdades básicas mais importantes apontado por Rawls (1997, p. 65): Liberdade política (direito de votar e de ocupar uma função pública), liberdade de expressão e de reunião; liberdade de consciência e de pensamento; as liberdades da pessoa (proteção contra a opressão psicológica e agressão física; direito à propriedade privada e a proteção contra a prisão e detenção arbitrárias).

${ }^{4}$ Baseado no princípio do ótimo de Pareto, que "afirma que uma dada configuração é eficiente quando é impossível alterá-la de forma tal que pelo menos um dos sujeitos melhore a sua posição sem que pelo menos um outro fique numa posição pior" (1997, p. 72).

${ }^{5}$ Trata-se, estritamente falando, de um princípio maximizador: deve-se visar uma maximização das expectativas da posição menos favorecida obedecendo às limitações exigidas, contanto que isso traga benefícios para todos.
} 
Artigo: Limites da tolerância e liberdade de expressão: considerações à luz do pensamento de John Rawls em Uma teoria da justiça

- Sistema de liberdade natural (entrecruzamento de a1 com b1);

- Igualdade Liberal (entrecruzamento de a1 com b2);

- Aristocracia natural (entrecruzamento de a2 com b1);

- Igualdade democrática (entrecruzamento de a2 com b2).

De acordo com a avaliação rawlsiana, a distorção mais óbvia do sistema de liberdade natural é que ele permite que a distribuição seja influenciada por fatores arbitrários como talentos e habilidades naturais, cujo desenvolvimento ou não desenvolvimento acaba sendo favorecido por circunstâncias sociais e eventualidades fortuitas. A interpretação liberal corrige essa distorção quando assinala que "as posições não devem ser abertas apenas de um modo formal, mas que todos devem ter uma oportunidade equitativa de atingi-las" (1997, p. 77). Para que as expectativas daqueles com as mesmas habilidades e aspirações não sejam afetadas por sua classe social, deve-se impor ao sistema social condições estruturais básicas adicionais que preservem a igualdade equitativa de oportunidades. No que tange ao ideal aristocrático, nele não se tenta regular as contingências sociais além do que exige a igualdade formal de oportunidades, entretanto os benefícios dos que detêm maiores dotes naturais limitam-se àqueles que aumentam as vantagens dos menos favorecidos. Chega-se à igualdade democrática por meio da combinação do princípio das oportunidades equitativas com o princípio da diferença. Supondo a estrutura de instituições exigidas pelo primeiro princípio e pela igualdade equitativa de oportunidades, as maiores expectativas daqueles em melhor situação são justas se, e somente se, funcionam como parte de um esquema que melhore as expectativas dos membros menos favorecidos da sociedade.

Com base nesses desdobramentos do segundo princípio de justiça, Rawls (1997, p. 88) apresenta uma segunda formulação dele: "As desigualdades econômicas e sociais devem ser ordenadas de modo a serem ao mesmo tempo (a) para o maior benefício esperado dos menos favorecidos e (b) vinculadas a cargos e posições abertos a todos em condições de igualdade equitativa de oportunidades". A parte b do segundo princípio deve ser entendida como princípio liberal da igualdade equitativa de oportunidades (p.89). De acordo com o que Rawls desenvolve no $\S 17$, estando ligado ao princípio da diferença, o princípio da igualdade eqüitativa - realizando, em parte, a ideia de que é necessário reparar o desvio das contingências, compensando desigualdades de nascimento e de dotes naturais imerecidas; expressando uma concepção de reciprocidade, isto é, sendo um princípio de benefício mútuo; e fornecendo uma interpretação do princípio de fraternidade que o torne um padrão perfeitamente factível — não conduz a uma ordem social meritocrática. Para Rawls, esse 
princípio da igualdade equitativa de oportunidades deve assegurar também que o sistema de cooperação seja um sistema de justiça procedimental pura ${ }^{6}$, cuja característica distintiva, segundo ele próprio, "é que o processo para determinação do resultado justo deve ser realmente levado a cabo; pois nesses casos não há critério independente em referência ao qual se pode demonstrar que um resultado definitivo é justo" (RAWLS, 1997, p. 92). Assim sendo, um procedimento equitativo traduz a sua equidade no resultado somente quando é efetivamente realizado. Desse modo, a aplicação da noção de justiça procedimental pura às partes distributivas exige construir e administrar um sistema justo de instituições (p. 93).

Dado que os princípios de justiça foram abordados na primeira parte de sua famosa obra sem levar em conta formas institucionais, John Rawls pretende, na parte II Instituições —, ilustrar o conteúdo daqueles, descrevendo uma estrutura básica que os satisfaça. Ele lembra que as principais instituições desta estrutura básica são as de uma democracia constitucional. Assim sendo, bem no início do § 43, Rawls (1997, p. 303) afirma que "os princípios da justiça se aplicam à estrutura básica e regulam o modo como suas mais importantes instituições se organizam". Antes, no $\$ 31$, ele estabelecera uma sequência de quatro estágios ${ }^{7}$, apresentando-a como um recurso para aplicação da teoria da justiça como equidade para as instituições. Considerando que cada um dos princípios de justiça regula ou governa instituições em um domínio particular, Rawls assinala que o princípio da liberdade igual é o padrão primário para a convenção constituinte, determinando assim que a constituição estabeleça um status comum seguro de cidadania igual e implemente a justiça política. O segundo princípio atua no estágio da legislatura, determinando que as políticas sociais e econômicas maximizem as expectativas dos menos favorecidos. Uma segunda parte

\footnotetext{
${ }^{6}$ No $§ 14$, John Rawls (1997, p. 91-94) destaca que a noção de justiça procedimental pura é mais bem entendida quando comparada com a justiça procedimental perfeita e com a justiça procedimental imperfeita. Ilustrada pela divisão de um bolo em partes iguais, a Justiça procedimental perfeita apresenta um critério prévio para decidir qual resultado é justo e um procedimento que com certeza conduzirá a ele. No caso da justiça procedimental imperfeita, exemplificada pelo julgamento num processo criminal, embora exista um critério independente para produzir o resultado correto, não há um processo factível que com certeza leve a ele. A justiça procedimental pura caracteriza-se pela inexistência de um critério independente para definir qual resultado é justo (em contraste com a justiça procedimental perfeita em que tal critério existe e é definido antes de o processo acontecer) e pela existência de um procedimento que quando corretamente aplicado produz necessariamente um resultado correto ou justo (em contraste com a justiça procedimental imperfeita na qual tal processo factual inexiste). A vantagem prática da justiça procedimental pura é que ela evita o problema da definição de princípios que deem conta da complexidade resultante da infindável variedade de circunstâncias e das posições relativas variáveis dos indivíduos.

${ }^{7}$ Resumidamente, a sequência de quatro estágios é a seguinte: $1^{\circ}$ ) Princípios de justiça escolhidos na posição original sob o véu de ignorância; $2^{\circ}$ ) Convenção constituinte: as partes, depois de terem adotado os princípios de justiça escolhidos anteriormente, devem propor um sistema para os poderes constitucionais de governo e os direitos básicos dos cidadãos; $3^{\circ}$ ) No estágio legislativo, são estabelecidos institutos legais que devem levar em
} 
Artigo: Limites da tolerância e liberdade de expressão: considerações à luz do pensamento de John Rawls em Uma teoria da justiça

da estrutura básica deve conter as distinções e hierarquias das formas sócio-políticoeconômicas que garantam a cooperação social eficaz e mutuamente benéfica (1997, p. 215 et seq.).

Após esta imersão nas considerações feitas por Rawls acerca da teoria da justiça como equidade e suas implicações, temos então condições para, de um modo mais contextualizado, explicitar o seu posicionamento acerca da liberdade de expressão. Para tanto, será necessário considerar mais detidamente as seções 32-35 do capítulo IV — Liberdade igual — que abre a segunda parte da obra originariamente publicada em 1971.

\section{MARCOS REFERENCIAIS PARA UMA ANÁLISE RAWLSIANA DA LIBERDADE DE EXPRESSÃO}

No capítulo IV, após apresentar a sequência de quatro estágios (ver nota 7 supra) e ter definido o conceito de liberdade ( $(32)$, J. Rawls discute o primeiro problema da liberdade igual que é o da liberdade igual de consciência ${ }^{8}$ (§ 33), articulando-o com a questão da tolerância [tolerância e interesse comum (§34) e tolerância para com os intolerantes (§35)]. Será no âmbito dessa discussão que poderemos encontrar subsídios para a explicitação da análise rawlsiana da liberdade de expressão.

Nas supracitadas seções, Rawls não aborda diretamente a questão da liberdade de expressão ${ }^{9}$. Entretanto, nas análises ali desenvolvidas, ele assinala que, embora tenha tomado como exemplo a liberdade de consciência para mostrar de que modo a justiça como equidade oferece fortes argumentos a favor da liberdade igual, o mesmo tipo de raciocínio pode ser generalizado para aplicar-se a outras liberdades (1997, p. 223). Mais adiante, quando trata da tolerância para com os intolerantes, ele diz que discutirá esse assunto relacionando-o com a tolerância religiosa, todavia, fazendo as devidas alterações, a demonstração pode estender-se a outros casos (1997, p. 235). Considerando que, no seu comentário ao primeiro princípio da

conta não apenas os princípios da justiça, mas também respeitar os limites constitucionais; $4^{\circ}$ ) Aplicação das regras a casos particulares por parte de juízes e administradores e observância delas por parte dos cidadãos.

${ }^{8}$ Os outros dois problemas da liberdade igual discutidos no capítulo IV são os seguintes: justiça política e direitos políticos iguais e liberdade igual da pessoa e sua relação com o estado de direito.

${ }^{9}$ Salvo melhor juízo, ele apenas a cita uma vez para ilustrar a necessidade de se perceber se um instituto legal de uma lei realmente restringe ou simplesmente regula uma determinada liberdade básica; e outra vez quando diz da necessidade de se avaliar uma liberdade básica com relação a outra. Respectivamente: "Por exemplo, certas regras de método são necessárias para regular uma discussão; sem a aceitação de procedimentos razoáveis de indagação e debate, a liberdade de expressão perde seu valor." e "[...] mas, em muitos outros pontos, terão de avaliar uma liberdade básica com relação a outra; por exemplo, a liberdade de expressão com o direito a um julgamento justo" (1997, p. 220). 
justiça que assegura liberdades básicas iguais, John Rawls situou, dentre as mais importantes, a "liberdade de expressão e reunião" (p. 65), pode-se então propor que as análises empreendidas nas seções 32-35 servem de balizas referenciais para podermos pensar a questão da liberdade de expressão ${ }^{10}$.

Feitas essas observações, podemos agora nos fixar nas seções compostas pelos $\S \S 32-$ 35, detectando nelas os referenciais balizadores que nos ajudarão na explicitação do ponto de vista rawlsiano acerca da liberdade de expressão.

Rawls começa o $\S 32$ sustentando que o debate entre os proponentes da liberdade negativa e os da positiva não diz respeito à definição de liberdade, mas sim ao valor relativo das várias liberdades quando conflitam entre si (p. 218). Por isso, passando ao largo dessa questão, ele presume "que qualquer liberdade pode ser explicada mediante uma referência a três itens: os agentes que são livres, as restrições ou limitações de que eles estão livres, e aquilo que eles estão livres para fazer ou não" (p. 219). Com base nesta estrutura triádica, uma liberdade tem a seguinte descrição geral: "esta ou aquela pessoa (ou pessoas) está (ou não está) livre desta ou daquela restrição (ou conjunto de restrições) para fazer (ou não fazer) isto ou aquilo" (p. 219). Como pretende discutir a liberdade em conexão com limitações legais e constitucionais, aquela se liga a certa estrutura de instituições, a um determinado sistema de normas públicas que definem direitos e deveres; desse modo, uma pessoa tem liberdade quando está livre de restrições legais e quando os demais têm um dever estabelecido por lei de

\footnotetext{
${ }^{10}$ Numa perspectiva externa ao texto de Rawls, encontramos uma justificativa deste ponto de vista nas análises de Monique Canto-Sperber em sua conferência pronunciada no foro internacional sobre a intolerância. Ela diz: "Como os autores liberais também observaram, a liberdade de opinião de nada vale se não for acompanhada da liberdade de falar, de tentar convencer e de publicar, e isso está perfeitamente explicado em Espinosa. [...] diz ele, [...] 'os homens não podem impedir-se de confiar uns aos outros seus projetos, mesmo quando o silêncio é requerido'". Mais adiante ela lembra o posicionamento de Stuart Mill que considera a liberdade de expressarmos nosso pensamento e de tornar públicas nossas opiniões quase tão importante quanto a própria liberdade de pensar e dela praticamente indissociável. (CANTO-SPERBER, 2000, p. 91 et seq.). Também Ricoeur (1991, p. 295) apresenta um posicionamento que confirma essa perspectiva. Nesse texto, ele visa distinguir os níveis de aplicação (institucional, cultural e religioso-teológico) dos conceitos de tolerância e intolerância, tomando como pedra de toque a autenticidade ou inautenticidade do grito de indignação "intolerável". Fixando o foco na análise que Ricoeur faz da questão da tolerância no plano institucional, nota-se que, para a o filósofo francês, a perda da unção eclesiástica por parte do poder político e a perda da sanção política pela instituição eclesiástica proporcionaram o surgimento da noção de tolerância como abstenção de interditar e de exigir. A dessacralização do poder possibilita o surgimento do Estado de direito, cuja marca distintiva objetiva, para Ricoeur, é a amplitude do espaço de liberdade resultante da noção de tolerância como abstenção. De tal forma que o estado de direito moderno emerge então marcado por essa tolerância-abstenção e pelas liberdades dela resultantes (liberdade de expressão, de reunião, de culto, de ensino ...). Na busca de uma justificação positiva para essa abstenção do Estado e para as liberdades dela resultantes, Ricoeur diz que a encontra na ideia de justiça. Nesse ponto, reconhece o encorajamento que encontrou na grande obra de John Rawls - Uma teoria da Justiça. Nela, como já foi apontado mais acima, o filósofo de Harvard propôs uma dupla formulação do princípio da justiça. De acordo com a leitura ricoeuriana, e é isso que nos interessa destacar no momento, no plano da igual cidadania, liberdade de expressão e liberdade de consciência coincidem (grifo nosso), pois, a consciência (o foro interior), sem expressão e sem comunicação, permaneceria muda (RICOEUR, 1991, p. 299).
} 
Artigo: Limites da tolerância e liberdade de expressão: considerações à luz do pensamento de John Rawls em Uma teoria da justiça

não interferir. Ou seja, um intricado conjunto de direitos e deveres caracteriza qualquer liberdade básica particular, de tal forma que liberdade não só implica que seja permissível fazer ou não determinada coisa, mas também que o governo e outras pessoas tenham a obrigação legal de não criar obstáculos.

Entretanto, salienta Rawls (1997, p. 220), as liberdades básicas devem ser avaliadas como um sistema único, isto é, o valor de uma delas depende da especificação das outras, de tal forma que "a melhor ordenação das várias liberdades depende da totalidade das limitações a que elas estão sujeitas". Mediante o que acaba de ser assinalado, as liberdades básicas, para o filósofo, admitem ser restringidas. Todavia, ele observa que "essas limitações estão sujeitas a certos critérios expressos pelo significado da liberdade igual e pela ordem serial dos dois princípios da justiça" (p. 220). De acordo com esse duplo critério, uma liberdade só pode ser limitada para garantir que ela ou outra liberdade básica esteja adequadamente protegida, de tal forma que o sistema único de liberdades esteja mais bem ordenado. Ou seja, a violação de alguma das liberdades básicas iguais não pode ser justificada nem compensada por maiores vantagens econômicas e sociais. Em suma: a liberdade só pode ser limitada em nome da própria liberdade.

Na seção seguinte ( $\$ 33$ ), John Rawls discute a relação do primeiro princípio de justiça com a liberdade de consciência. Para ele, a justiça como equidade propicia fortes argumentos a favor da liberdade de consciência igual. O raciocínio utilizado pelo filósofo para demonstrar sua tese - e que pode ser generalizado às outras liberdades básicas, incluindo evidentemente a liberdade de expressão - , em suma, é o seguinte: considerando que as pessoas, na posição original, veem-se a si mesmas como portadoras de interesses morais, religiosos ou filosóficos que não podem arriscar perder, exceto se não houver alternativas, parece evidente que as partes devem escolher princípios que assegurem a integridade de sua liberdade moral e religiosa. Encobertas pelo véu de ignorância, tais pessoas não sabem quais são suas convicções religiosas e morais e nem como são vistas no seio da sociedade a que pertencem, ou seja, se são apoiadas por uma maioria ou por uma minoria. Emerge então, a partir desse contexto, a questão acerca da decisão de qual princípio deve ser adotado para regular as liberdades dos cidadãos no que tange aos interesses de natureza religiosa, filosófica e moral. Levando em conta que as partes não podem correr riscos envolvendo a sua liberdade, por exemplo: permitindo que doutrinas dominantes persigam ou eliminem as demais se o pretender, parece razoável que a igual liberdade de consciência seja o único princípio que as pessoas na posição original devem reconhecer. 
No $§ 34$, Rawls, a partir da relação entre tolerância e interesse comum, passa a analisar a questão da prioridade da liberdade. Ele inicia a abordagem dessa problemática considerando que determinadas questões estão fora do âmbito de competência do governo, cuja tarefa é a de garantir condições de igual liberdade. Contudo, quando o governo exerce os seus poderes limitando a liberdade com base no interesse geral na ordem e segurança públicas, ele está como agente dos cidadãos, amparado no fato de a manutenção da ordem pública ser a condição necessária para que se garanta um sistema de liberdades iguais. Depreende-se então o seguinte padrão: "uma liberdade só deve ser limitada quando há suposições razoáveis de que não o fazer implica prejuízo para a ordem pública que o governo deve manter" (RAWLS, 1997, p. 231, grifo nosso). Tal padrão não viola a liberdade igual de ninguém, e está em consonância com o que foi estipulado mais acima quando se disse que a única razão para negar o princípio da liberdade igual é a de evitar uma injustiça ou perda de liberdade ainda maior.

A ideia de que "a liberdade é regida pelas condições necessárias da própria liberdade" (RAWLS, 1997, p. 234), faz com que tolerância não se origine de necessidades práticas ou razões de Estado, mas encontre seu fundamento no próprio princípio da liberdade igual. À luz dessa perspectiva, muitos dos motivos de intolerância vigentes no passado $^{11}$ não podem mais ser aceitos, já que colidem com o primeiro princípio. Então, no início do § 35, pergunta Rawls: a justiça exige que se tolerem os intolerantes? Se for o caso, em quais condições? Ele discute essa problemática relacionando-a com a tolerância religiosa, mas ressalta que, conforme já foi lembrado anteriormente, "feitas as devidas alterações, a demonstração pode estender-se a outros casos" (p. 235). A análise que ele desenvolve nesse item encaminha-se para a seguinte constatação: embora uma facção intolerante não tenha direito de se queixar de intolerância, não se pode dizer que os grupos tolerantes tenham por isso direito de suprimi-la, pois isso significaria que uma liberdade igual estaria sendo negada sem uma razão suficiente. A menos que, sinceramente e com razões consistentes, o tolerante acreditar que a intolerância para com os intolerantes é necessária para sua própria segurança, o fato de alguém ser intolerante não é razão suficiente para que sua liberdade seja limitada. Rawls acredita que numa sociedade bem ordenada e regulada pelos princípios da justiça como equidade existem forças de estabilização que visam a preservação da justiça da ordem global. Desse modo, se uma facção intolerante aparecer numa sociedade bem ordenada, as forças de estabilidade das

\footnotetext{
${ }^{11}$ Por exemplo aqueles baseados em princípios teológicos ou questões de fé, onde nenhuma argumentação é possível.
}

Sapere aude - Belo Horizonte, v. 9 - n. 17, p. 85-99, Jan./Jun. 2018 - ISSN: 2177-6342 
Artigo: Limites da tolerância e liberdade de expressão: considerações à luz do pensamento de John Rawls em Uma teoria da justiça

instituições justas procurarão convertê-la para a perspectiva da liberdade igual. No entanto, se houver riscos consideráveis para a manutenção do sistema de liberdades iguais, os tolerantes podem de maneira apropriada forçar os intolerantes a respeitarem a liberdade dos demais. De qualquer forma, o cerceamento da liberdade dos intolerantes é uma situação extrema, necessária somente quando os tolerantes acreditam que a sua segurança e a das instituições de liberdade estão ameaçadas pela intolerância. Concretamente, para o filósofo de Harvard, o estabelecimento de uma constituição justa que garanta a liberdade da cidadania igual é o princípio norteador: de acordo com Rawls (1997, p. 238), não há razão para negar a liberdade aos intolerantes enquanto a constituição em si estiver assegurada, contudo, em determinadas circunstâncias (quando as pessoas tolerantes justificadamente acreditam que a sua própria segurança e a das instituições de liberdade estão em perigo), "a liberdade dos intolerantes deve ser limitada para preservar a liberdade sob uma constituição justa" (p. 239).

\section{CONSIDERAÇÕES FINAIS}

O escopo principal deste texto foi discutir, à luz de uma abordagem propedêutica da Teoria da justiça como equidade de John Rawls, a problemática da justificativa para a intolerância e dos limites da tolerância e sua incidência no âmbito da liberdade de expressão. Com base no exame acima apresentado, concebemos que a argumentação desenvolvida nas seções 32-35 de Uma teoria da justiça constitui o marco referencial que nos possibilita pensar essa questão no quadro do pensamento rawlsiano desenvolvido na obra de 1971. Como pôde ser observado, a análise culminou no aspecto político-jurídico dos limites da tolerância. Resta-nos agora explicitar — recorrendo às análises de Paul Ricoeur (1991) — a incidência desse aspecto para a liberdade de expressão.

De acordo com a opinião do filósofo francês, no âmbito do primeiro princípio de justiça de Rawls, fica-se restrito à ideia de tolerância como abstenção. Entretanto, na perspectiva do segundo princípio que convida a escolher o arranjo social menos desfavorável aos mais desfavorecidos, isto é, que preconiza a justa repartição como sendo aquela oposta ao princípio sacrificial, pode-se passar de uma visada em que o Estado de direito não só assegura o aspecto formal da liberdade (cidadania igual) mas também seu aspecto material (oportunidades equitativas). Sob a ótica da "minimização da vitimização", apenas a proteção contra a obstrução não é suficiente, devem-se levar em conta os interesses concretos dos grupos mais minoritários. Passa-se então para uma noção mais positiva de tolerância que é a 
de reconhecer o direito à existência das diferenças. A compreensão positiva da tolerância como admissão do outro enquanto outro implica, em sintonia com o que preconiza o segundo princípio da justiça, que se estipulem concretamente as condições materiais de exercício da liberdade de expressão dos grupos mais frágeis. Deve-se também pensar em medidas corretivas a respeito dos abusos resultantes da pretensão dos mais fortes de se sobreporem a esfera de exercício da livre expressão dos menos favorecidos. Assim sendo, lembrando que, em Rawls, a defesa das liberdades exige a defesa da ordem pública, isto é, exige "regras de ordem" e que tal defesa é necessária porque as esferas de liberdades conflitantes tendem a se sobreporem umas sobre as outras, Ricoeur salienta então que, nesse sentido, as "regras de ordem" limitam de fato a liberdade de expressão.

Para Ricoeur, a distinção entre "regras de ordem" que asseguram a liberdade de expressão, e regras que restringem o conteúdo dos discursos é o ponto delicado dessa questão. De acordo com o filósofo, as regras de ordem só visam, em princípio, aumentar os benefícios da liberdade. Todavia, ele reconhece que nos encontramos numa encruzilhada perigosa: entre a tendência de sobreposição das esferas de liberdades rivais e a tendência "ideológica" de a instituição pública confundir "regras de ordem" com regras dirigidas contra o conteúdo de certos discursos. Essa pulsão sempre renascente do poder político em dizer a verdade em vez de se limitar a exercer a justiça constitui, no plano institucional, o intolerável, cuja face no plano individual é o abjeto, aquilo que não merece respeito. Esses dois critérios apresentados por Paul Ricoeur para a determinação do intolerável, acrescentados à concessão rawlsiana de que "a liberdade dos intolerantes deve ser limitada para preservar a liberdade sob uma constituição justa", impedem que a tolerância seja apenas um ideal moral abstrato e incapaz de fornecer, por si só, um critério que assegure a limitação de sua própria aplicação, por exemplo, no âmbito da liberdade de expressão.

\section{REFERÊNCIAS}

CANTO-SPERBER, Monique. Tolerância, neutralidade e pluralismo na tradição liberal. Foro Internacional sobre Intolerância: 1997, Paris, França. A intolerância. Rio de Janeiro: Bertrand Brasil, 2000, p. 88-97.

HÉRITIER, Françoise. O eu, o outro e a intolerância. Foro Internacional sobre Intolerância: 1997, Paris, França. A intolerância. Rio de Janeiro: Bertrand Brasil, 2000, p. 20-23.

MENDUS, Susan. Tolerância. In: CANTO-SPERBER, Monique. Dicionário de ética e filosofia moral. São Leopoldo, RS: Ed. Unisinos, 2013, p. 1030-1033. 
Artigo: Limites da tolerância e liberdade de expressão: considerações à luz do pensamento de John Rawls em Uma teoria da justiça

MONTAIGNE, Michel de. Ensaios. São Paulo: Abril Cultural, 1972.

RAWLS, John. Uma teoria da justiça. São Paulo: Martins Fontes, 1997.

RICOEUR, Paul. Etapa atual do pensamento sobre a intolerância. Foro Internacional sobre Intolerância: 1997, Paris, França. A intolerância. Rio de Janeiro: Bertrand Brasil, 2000.

RICOEUR, Paul. Tolérance, intolérance, intolérable. In: RICOEUR, Paul. Lectures 1: autour du politique. Paris: Éditions du Seuil, 1991. 